\title{
Evaluation of postural stability in girls and boys during the adolescence period
}

\author{
DOI: https://doi.org/10.5114/pq.2020.100289
}

\author{
Katarzyna Burdacka', Wiesław Chwała ${ }^{2}$, Robert Walaszek', Marcin Burdacki ${ }^{3}$ \\ ${ }^{1}$ Department of Recreology and Biological Regeneration, University of Physical Education in Krakow, Krakow, Poland \\ 2 Department of Biomechanics, University of Physical Education in Krakow, Krakow, Poland \\ ${ }^{3}$ Institute of Physiotherapy, Faculty of Health Sciences, Jagiellonian University, Krakow, Poland
}

Abstract

Introduction. The purpose of the work was to assess the static and dynamic postural stability and to identify the risk of the locomotor system injuries in 14-year-old boys and girls.

Methods. The study involved a group of 40 girls and 43 boys aged 14 who regularly attended physical education classes, 4 hours per week. The examination of static balance was carried out with the modified version of the first test of the Eurofit Physical Fitness Test Battery - the Flamingo Balance Test, and dynamic balance assessments were performed with the YBalance Test by using a specially designed test tool, the so-called Y-Balance Test Kit. To differentiate between the higher and lower risk of a motor system injury, an index proposed by Butler was applied.

Results. With respect to both static and dynamic balance, the results obtained by the studied girls did not differ statistically significantly from those of the studied boys.

Conclusions. In the group of girls, the index recommended by Butler was exceeded by $78 \%$ of the subjects for the left lower limb and by $80 \%$ of the subjects for the right one, while in the group of boys, the respective values were $74 \%$ and $79 \%$. This indicates that the risk of a motor system injury among the study subjects was low.

Key words: postural stability, static balance, dynamic balance, motor system injuries

\section{Introduction}

Balance is one of the most important coordination-related human motor capabilities. Virtually every motion task involves it, making it an integral part of the daily life of a human being [1]. The ability to maintain body balance, contrary to appearances, is a highly complex operation. This may be confirmed just by observation of young children who are still learning to stand and to walk unassisted - when their vertical position is lost, they have to make a big effort to regain it [2]. The difficulty to maintain a stable posture is caused by the fact that the body is composed of many mutually mobile segments connected by joints, thus forming a biokinematic chain [3]. In addition, other systems, such as the visual, vestibular, or sensory ones, are involved in balance maintenance. They indicate the current position of the body through the stimuli received by the receptors. For the entire mechanism to work properly, a mutual coordination between the musculoskeletal system and the central nervous system is required [4].

A person maintaining vertical body position is exposed to destabilizing stimuli. Their task is then to execute corrective movements which restore the proper position of the centre of gravity, displaced previously beyond the stability area [5].

Postural stability is defined as the ability of the body to maintain its vertical position independently and to regain balance after it was subject to disturbing forces [6]. Studies of postural stability are conducted in two domains. The first one is static balance; the tests are carried out in a free standing position, where the body is affected only by the gravity forces and by those generated by the balance control system [7].
The most popular tests applied to assess static balance are Romberg's test, often used in neurology, and the Flamingo Balance Test, known from the Eurofit Physical Fitness Test Battery. The second domain is dynamic balance, which is present during motion, where interactions of internal and external forces are involved, acting on the body centre of gravity of the examined subject in the gravitational field. In cyclic motion, such as gait or running, it is associated with the need for alternating balance loss and recovery. The requirements for the cerebellum to oversee dynamic balance are much greater than in static balance control. Coordination of visual stimuli, balance, and proprioception is particularly difficult in the presence of additional external disturbances. The introduction of specific distortions during various motor tasks allows researchers to analyse the emerging postural reactions and to expand their knowledge of balance control. Focusing research problems only on the assessment of static balance seems insufficient for the risk of potential injuries during physical activity. This becomes especially important during puberty, when the bones of the limbs, which form bone levers for muscle syndromes, quickly lengthen. A consequence of rapid growth changes in the movement apparatus is a disruption of the existing movement regimens resulting from the altering proprioception and the ascending pathways of the spinal cord. This poses a particular risk of injuries during physical activity [3]. The most common tests to assess this type of balance are the Star Excursion Balance Test and the Y-Balance Test (YBT) [8].

YBT is an innovative research tool that allows to estimate the level of postural stability in humans and thus to determine

Correspondence address: Robert Walaszek, Department of Recreology and Biological Regeneration, University of Physical Education in Krakow, al. Jana Pawła II 78, 31-571 Krakow, Poland, e-mail: robertwalaszek63@gmail.com 
the risk of balance loss and consequent injuries of the motor system [9]. At present, there are still few reliable studies using YBT. Herrington et al. [10] were among the first researchers to show the relationship between YBT results and the presence of instability of the talocrural joint. Lee et al. [4] looked for relationships between the values obtained in YBT and the lower limb strength in a group of adults. Walaszek et al. [11] demonstrated that the results obtained in YBT depended on muscle strength and mobility of the joints of the lower limbs of the examined 14-year-olds.

Although, on the whole, girls enter puberty earlier than boys, both genders at the age of around 14 show a clear reluctance to perform physical exercises and participate in physical education classes. Therefore, in order to assess the risk of injury in groups of young people going through their puberty, it is important to use reliable and not technologically advanced tests for both static and dynamic balance [12].

On a global scale, the literature on the assessment of the postural stability in both boys and girls during their puberty is scarce [13]. The authors of the paper assumed that carrying out such studies could assist in determining the predispositions and ability of young people who were going through their puberty to do certain sports, and possibly in predicting the risk of motor system injuries. Girls who practise sport during their puberty are found to have a much higher incidence of certain non-contact lower limb injuries compared with their male counterparts. Poorer postural stability, especially the one measured in dynamic conditions, is a risk factor for lower limb injuries (the most common being twists and sprains of the ankle joint and anterior knee ligament damage), but so far, very few studies have assessed intersex differences in this stability during the specific period of adolescence. Only a few scientific reports show different profiles of postural stability in girls and boys during adolescence [8, 13-15]. The purpose of the work was to assess the static and dynamic postural stability and to identify the risk of the locomotor system injuries in 14-year-old boys and girls. Achieving the set objective will make it possible to assess the balance of girls and boys of this age in a better way than in the studies performed so far, especially in the area of spatial body control during the movement of the centre of gravity while performing balance tests.

\section{Subjects and methods}

\section{Participants}

The study investigated a group of 40 girls and 43 boys aged 14 years who regularly attended physical education classes, 4 hours per week. The examinations for the needs of this work were carried out at Gymnasium No. 2 in Skawina, Poland, in October 2018. They were performed in the gym during the morning hours, with the consent of the school management and the parents of the children involved.

\section{Interventions}

\section{Measurements of somatic parameters and diagnosis of lateralization}

Basic somatic parameters were measured within this work: body height and weight. An anthropometer (Martin type, USA) was used to assess body height with 1-cm accuracy. Body weight was evaluated with electronic scales (Radwag, WPT $100 / 200$ OW) with a $0.1-\mathrm{kg}$ accuracy. Diagnosis of later-

\section{Examination of postural stability in static conditions}

The assessment of static balance was carried out with a modified version of the first test of the Eurofit Physical Fitness Test Battery - balanced single-leg stance (Flamingo Balance Test). The modification consisted in a different method of measurement during the examination as compared with the original version of the test. The duration of 2 attempts was measured with 1-second accuracy, separately for the left and right lower limbs, until the subject lost their balance. It was the better result that was recorded in the examination card [17].

\section{Examination of postural stability in dynamic conditions}

Dynamic balance was assessed with use of YBT $[11,18]$. In accordance with the instructions of the YBT inventors, a specially constructed diagnostic tool was applied: the so called YBT Kit. The measurement procedure followed the guidelines by Plisky et al. [19] and Shaffer et al. [20]. Three trials were executed for each lower extremity and for each movement direction. If the test was started with the left lower extremity, the subject performed the first 3 trials standing on the left lower limb and reaching forward (anterior reach) with the right one. In the next 3 trials, the right lower extremity was the stance extremity and the left one - the reach extremity, with the same reach direction. This trial mode was repeated with measurements for the posteromedial and posterolateral directions. The measurements of the distance of the indicator moved from the central platform were taken with $0.5-\mathrm{cm}$ accuracy. The trial was deemed successful when the subject was able to return to the starting position after they had performed the movement. When the test was completed, relative lengths of both lower extremities were measured with $0.5-\mathrm{cm}$ accuracy. During the analysis of the results, the highest achieved reach result in each direction during unilateral stance was corrected for the length of the stance extremity, in accordance with the following formula:

$$
\operatorname{MAXD}(\%)=[D D / L L] \times 100
$$

where: MAXD - the maximum reach distance in one direction, $\mathrm{DD}$ - distance of reach in one direction, $\mathrm{LL}$ - relative length of the leg.

The composite YBT score was calculated for each subject with the following formula:

$$
\text { YBT-CS }(\%)=[(A N+P M+P L) /(L L \times 3)] \times 100
$$

where: YBT-CS - YBT composite reach score, AN - anterior reach, $\mathrm{PM}$ - posteromedial reach, $\mathrm{PL}$ - posterolateral reach, $\mathrm{LL}-$ relative length of the leg.

\section{Determination of the risk of the motor system injury}

The index proposed by Butler et al. [9] was used to differentiate between the higher and lower risk of motor system injury. Global YBT results for both extremities that were lower than $89.6 \%$ were indicative of a higher risk of motor system injuries (a 3.5-fold increase); the results exceeding this percentage value were related to a lower risk of injuries. To facilitate the interpretation of the results, in specially designed tables, the subjects who exceeded the $89.6 \%$ limit were assigned the rank ' 1 ,' and those who did not exceed this limit were ranked ' 0 '. The results were then summed up and presented as percentage values. 


\section{Statistical methods}

The statistical analysis was performed with use of the SPSS 13.0 software. Basic descriptive statistics were calculated: the average value and standard deviation. The Shapiro-Wilk $W$ test was applied to assess the distribution of the test variables. For comparative intergroup analysis, the $t$-test was used if the distributions were found to be close to normal, and if there were non-normal distributions, the Mann-Whitney $U$ test was employed. The significance level was assumed at $p \leq 0.05$.

\section{Ethical approval}

The research related to human use has complied with all the relevant national regulations and institutional policies, has followed the tenets of the Declaration of Helsinki, and has been approved by the authors' institutional review board or an equivalent committee.

\section{Informed consent}

Informed consent has been obtained from the legal guardians of all individuals included in this study.

\section{Results}

Table 1 illustrates the age and somatic characteristics of the study participants.

Table 1. The differences in age and somatic characteristics between the examined girls and boys assessed with the $t$-test

\begin{tabular}{|c|c|c|c|c|c|c|}
\hline \multirow{2}{*}{ Variables } & \multicolumn{2}{|c|}{ Girls $(n=40)$} & \multicolumn{2}{|c|}{ Boys $(n=43)$} & \multirow{2}{*}{$\begin{array}{l}\text { Differ- } \\
\text { ence }\end{array}$} & \multirow{2}{*}{$p$} \\
\hline & $\bar{x}$ & $S D$ & $\bar{x}$ & $S D$ & & \\
\hline Age (years) & 13.93 & 0.29 & 13.88 & 0.29 & 0.05 & 0.452 (NS) \\
\hline Height (m) & 1.60 & 0.06 & 1.71 & 0.07 & 0.11 & $0.000^{\star *}$ \\
\hline Weight (kg) & 54.33 & 13.6 & 59.95 & 10.76 & 5.62 & $0.005^{\star}$ \\
\hline $\mathrm{BMI}\left(\mathrm{kg} / \mathrm{m}^{2}\right)$ & 21.17 & 4.55 & 20.35 & 3.21 & 0.82 & 0.699 (NS) \\
\hline
\end{tabular}

${ }^{*} p \leq 0.01,{ }^{* *} p \leq 0.001$

$\mathrm{BMI}$ - body mass index, NS - not statistically significant

Table 2. Shapiro-Wilk $W$ test assessment of distributions of static and dynamic balance parameters in the studied girls and boys

\begin{tabular}{|l|c|c|c|c|}
\hline \multirow{2}{*}{ Variables } & \multicolumn{2}{|c|}{ Girls $(n=40)$} & \multicolumn{2}{c|}{ Boys $(n=43)$} \\
\cline { 2 - 5 } & $W$ & $p$ & $W$ & $p$ \\
\hline FBT_L (s) & 0.59249 & $0.000^{*}$ & 0.74282 & $0.000^{*}$ \\
\hline FBT_R (s) & 0.65069 & $0.000^{*}$ & 0.78371 & $0.000^{*}$ \\
\hline Y-ANT_L (\%) & 0.99187 & 0.996 & 0.98035 & 0.661 \\
\hline Y-POST-MED_L (\%) & 0.95501 & 0.113 & 0.96508 & 0.212 \\
\hline Y-POST-LAT_L (\%) & 0.97468 & 0.499 & 0.98181 & 0.719 \\
\hline Y-CS_L (\%) & 0.97743 & 0.595 & 0.97891 & 0.605 \\
\hline Y-ANT_R (\%) & 0.97169 & 0.406 & 0.96604 & 0.229 \\
\hline Y-POST-MED_R (\%) & 0.98410 & 0.836 & 0.96702 & 0.249 \\
\hline Y-POST-LAT_R (\%) & 0.97640 & 0.558 & 0.96945 & 0.303 \\
\hline Y-CS_R (\%) & 0.97298 & 0.445 & 0.97813 & 0.575 \\
\hline
\end{tabular}

${ }^{*} p \leq 0.01$

FBT - Flamingo Balance Test, L - left, $R$ - right,

Y-ANT - Y-Balance Test anterior, Y-POST-MED - Y-Balance Test posteromedial, Y-POST-LAT - Y-Balance Test posterolateral,

Y-CS - Y-Balance Test composite score
Table 3. Comparative analysis of Flamingo Balance Test results in girls and boys

\begin{tabular}{|c|c|c|c|c|c|}
\hline \multirow[t]{2}{*}{ Variables } & $\begin{array}{c}\text { Girls } \\
(n=40)\end{array}$ & $\begin{array}{c}\text { Boys } \\
(n=43)\end{array}$ & \multirow[t]{2}{*}{$U$} & \multirow[t]{2}{*}{$Z$} & \multirow[t]{2}{*}{$p$} \\
\hline & \multicolumn{2}{|c|}{ Total ranks } & & & \\
\hline FBT_L (s) & 1871 & 1615 & 795.00 & 0.588 & 0.557 (NS) \\
\hline FBT_R (s) & 1823 & 1663 & 843.00 & 0.150 & 0.880 (NS) \\
\hline
\end{tabular}

FBT - Flamingo Balance Test, L - left, $\mathrm{R}$ - right,

NS - not statistically significant

Table 4. Comparative analysis of Y-Balance Test results in girls and boys

\begin{tabular}{|c|c|c|c|c|c|}
\hline \multicolumn{2}{|c|}{ Girls $(n=40)$} & \multicolumn{2}{|c|}{ Boys $(n=43)$} & \multirow{2}{*}{ Difference } & $p$ \\
\hline $\bar{x}$ & $S D$ & $\bar{x}$ & $S D$ & & \\
\hline 77.70 & 5.38 & 75.63 & 5.43 & 2.07 & $0.085(\mathrm{NS})$ \\
\hline 102.83 & 8.52 & 104.06 & 9.85 & 1.23 & $0.546(\mathrm{NS})$ \\
\hline 104.41 & 9.28 & 104.65 & 9.63 & 0.24 & $0.910(\mathrm{NS})$ \\
\hline 94.98 & 6.58 & 94.78 & 7.25 & 0.20 & $0.895(\mathrm{NS})$ \\
\hline 78.74 & 5.32 & 76.62 & 5.60 & 2.12 & $0.081(\mathrm{NS})$ \\
\hline 101.39 & 8.21 & 103.00 & 8.42 & 1.61 & $0.382(\mathrm{NS})$ \\
\hline 106.01 & 9.56 & 105.99 & 9.35 & 0.02 & $0.992(\mathrm{NS})$ \\
\hline 95.38 & 6.55 & 95.20 & 6.64 & 0.18 & $0.902(\mathrm{NS})$ \\
\hline
\end{tabular}

NS - not statistically significant

Table 2 presents the distributions of the examined variables. Both in girls and in boys, non-normal distributions were noted in 2 cases. They pertained to the left- and rightleg Flamingo Balance Test.

Table 3 presents the results of the comparative analysis (Mann-Whitney $U$ test) of static balance measured with the Flamingo Balance Test in girls and boys. In terms of static balance, the studied girls did not differ statistically significantly from the studied boys.

Table 4 shows the results of the comparative analysis of YBT in girls and boys obtained with the use of the $t$-test for independent samples. The studied girls did not differ statistically significantly from the examined boys with respect to dynamic balance in any of the evaluated test directions.

In the group of girls, the index recommended by Butler et al. [9] - $89.6 \%$ - was exceeded by $77.5 \%$ of the subjects for the left limb and $80 \%$ of the subjects for the right one this means that the vast majority of girls showed low propensity to motor system injuries resulting from loss of balance (Table 5).

In the group of boys, the index recommended by Butler et al. [9] - $89.6 \%$ - was exceeded by $74 \%$ of the subjects for the left limb and $79 \%$ of the subjects for the right one similarly to girls, the majority of boys showed low propensity to motor system injuries resulting from loss of balance (Table 6).

\section{Discussion}

Research on postural stability has so far been most commonly carried out in static conditions, such as single-leg or double-leg stance. The amplitudes of the centre of gravity projection swings out of the square of support were then assessed. However, most tests are currently performed in dynamic conditions, in which the ability to maintain balance is evaluated during a change of the fulcrum position [18]. 
Table 5. Analysis of global Y-Balance Test results in the context of higher or lower risk of motor system injury in the group of girls

\begin{tabular}{|c|c|c|c|c|}
\hline No. & Y-CS_L (\%) & Result & Y-CS_R (\%) & Result \\
\hline 1 & 95.06 & 1 & 97.97 & 1 \\
\hline 2 & 90.48 & 1 & 89.09 & 0 \\
\hline 3 & 89.16 & 0 & 96.79 & 1 \\
\hline 4 & 90.98 & 1 & 89.29 & 0 \\
\hline 5 & 105.06 & 1 & 103.00 & 1 \\
\hline 6 & 98.78 & 1 & 104.88 & 1 \\
\hline 7 & 100.00 & 1 & 101.59 & 1 \\
\hline 8 & 99.40 & 1 & 103.41 & 1 \\
\hline 9 & 91.58 & 1 & 92.31 & 1 \\
\hline 10 & 97.97 & 1 & 90.24 & 1 \\
\hline 11 & 86.52 & 0 & 91.93 & 1 \\
\hline 12 & 90.50 & 1 & 79.84 & 0 \\
\hline 13 & 92.42 & 1 & 92.13 & 1 \\
\hline 14 & 87.23 & 0 & 90.86 & 1 \\
\hline 15 & 101.36 & 1 & 100.39 & 1 \\
\hline 16 & 89.15 & 0 & 89.08 & 0 \\
\hline 17 & 111.73 & 1 & 107.61 & 1 \\
\hline 18 & 88.64 & 0 & 93.80 & 1 \\
\hline 19 & 100.00 & 1 & 95.12 & 1 \\
\hline 20 & 92.34 & 1 & 90.80 & 1 \\
\hline 21 & 94.57 & 1 & 92.88 & 1 \\
\hline 22 & 85.14 & 0 & 87.32 & 0 \\
\hline 23 & 84.54 & 0 & 82.81 & 0 \\
\hline 24 & 103.42 & 1 & 102.14 & 1 \\
\hline 25 & 87.04 & 0 & 90.19 & 1 \\
\hline 26 & 89.84 & 1 & 93.50 & 1 \\
\hline 27 & 100.00 & 1 & 100.38 & 1 \\
\hline 28 & 93.33 & 1 & 87.92 & 0 \\
\hline 29 & 99.25 & 1 & 98.13 & 1 \\
\hline 30 & 94.06 & 1 & 93.87 & 1 \\
\hline 31 & 98.21 & 1 & 100.00 & 1 \\
\hline 32 & 92.08 & 1 & 95.36 & 1 \\
\hline 33 & 97.39 & 1 & 98.59 & 1 \\
\hline 34 & 83.72 & 0 & 89.27 & 0 \\
\hline 35 & 105.22 & 1 & 103.21 & 1 \\
\hline 36 & 106.50 & 1 & 106.91 & 1 \\
\hline 37 & 96.36 & 1 & 103.10 & 1 \\
\hline 38 & 100.60 & 1 & 102.38 & 1 \\
\hline 39 & 97.32 & 1 & 94.83 & 1 \\
\hline 40 & 92.31 & 1 & 92.31 & 1 \\
\hline Sum 1 & \multicolumn{2}{|c|}{$31(77.5 \%)$} & \multicolumn{2}{|c|}{32 (80\%) } \\
\hline Sum 0 & \multicolumn{2}{|c|}{9 (22.5\%) } & \multicolumn{2}{|c|}{8 (20\%) } \\
\hline
\end{tabular}

Y-CS - Y-Balance Test composite score,

$76 \mathrm{~L}$ - left, $\mathrm{R}$ - right, 1 - score $\geq 89.6 \%$, 0: score $<89.6 \%$
Table 6. Analysis of global Y-Balance Test results in the context of higher or lower risk of motor system injury in the group of boys

\begin{tabular}{|c|c|c|c|c|}
\hline No. & Y-CS_L (\%) & Result & Y-CS_R (\%) & Result \\
\hline 1 & 98.28 & 1 & 103.53 & 1 \\
\hline 2 & 102.75 & 1 & 107.25 & 1 \\
\hline 3 & 91.12 & 1 & 88.53 & 0 \\
\hline 4 & 97.50 & 1 & 92.83 & 1 \\
\hline 5 & 96.01 & 1 & 93.48 & 1 \\
\hline 6 & 85.52 & 0 & 86.67 & 0 \\
\hline 7 & 86.05 & 0 & 88.10 & 0 \\
\hline 8 & 100.17 & 1 & 93.13 & 1 \\
\hline 9 & 98.47 & 1 & 94.19 & 1 \\
\hline 10 & 84.72 & 0 & 85.24 & 0 \\
\hline 11 & 108.24 & 1 & 108.42 & 1 \\
\hline 12 & 101.50 & 1 & 103.37 & 1 \\
\hline 13 & 92.01 & 1 & 98.26 & 1 \\
\hline 14 & 97.13 & 1 & 98.08 & 1 \\
\hline 15 & 95.69 & 1 & 99.25 & 1 \\
\hline 16 & 100.00 & 1 & 101.75 & 1 \\
\hline 17 & 98.11 & 1 & 101.89 & 1 \\
\hline 18 & 88.32 & 0 & 90.72 & 1 \\
\hline 19 & 105.94 & 1 & 99.34 & 1 \\
\hline 20 & 94.33 & 1 & 92.73 & 1 \\
\hline 21 & 82.58 & 0 & 84.08 & 0 \\
\hline 22 & 82.95 & 0 & 89.77 & 1 \\
\hline 23 & 88.48 & 0 & 92.91 & 1 \\
\hline 24 & 95.02 & 1 & 91.95 & 1 \\
\hline 25 & 97.22 & 1 & 97.75 & 1 \\
\hline 26 & 103.14 & 1 & 103.53 & 1 \\
\hline 27 & 102.38 & 1 & 101.19 & 1 \\
\hline 28 & 103.48 & 1 & 104.03 & 1 \\
\hline 29 & 85.06 & 0 & 91.19 & 1 \\
\hline 30 & 92.11 & 1 & 99.46 & 1 \\
\hline 31 & 96.71 & 1 & 93.80 & 1 \\
\hline 32 & 80.07 & 0 & 82.51 & 0 \\
\hline 33 & 94.04 & 1 & 92.55 & 1 \\
\hline 34 & 91.84 & 1 & 90.38 & 1 \\
\hline 35 & 88.41 & 0 & 86.23 & 0 \\
\hline 36 & 95.36 & 1 & 95.53 & 1 \\
\hline 37 & 97.35 & 1 & 94.89 & 1 \\
\hline 38 & 109.93 & 1 & 108.43 & 1 \\
\hline 39 & 95.14 & 1 & 94.04 & 1 \\
\hline 40 & 100.94 & 1 & 98.13 & 1 \\
\hline 41 & 89.92 & 1 & 88.12 & 0 \\
\hline 42 & 82.97 & 0 & 88.76 & 0 \\
\hline 43 & 98.57 & 1 & 97.67 & 1 \\
\hline Sum 1 & \multicolumn{2}{|c|}{32 (74\%) } & \multicolumn{2}{|c|}{34 (79\%) } \\
\hline Sum 0 & \multicolumn{2}{|c|}{$11(26 \%)$} & \multicolumn{2}{|c|}{$9(21 \%)$} \\
\hline
\end{tabular}

Y-CS - Y-Balance Test composite score,

L - left, R - right, 1 - score $\geq 89.6 \%$, 0 : score $<89.6 \%$ 
According to a large number of specialists, the physiological mechanisms and strategies of maintaining body posture in the upright position and keeping control over the course of movement activities are very different. Karimi and Solomonidis [21] have found no significant relationship between static and dynamic balance variables. They also believe that it is not entirely clear whether the level of dynamic balance can be determined and predicted on the basis of static balance level. Hrysomallis et al. [22] reached similar conclusions. Postural stability results measured with static tests differ from those achieved with dynamic tests.

Walaszek et al. [11] have shown that a high YBT score depends on the mobility of hip joints and knee joints and on the strength of knee joint extensors. In addition, they have demonstrated that the mobility of the ankle joint has only a minor effect on the YBT score. This is explained by a small contribution of this joint to the total range of motion as compared with the other 2 joints: knee and hip. Limited mobility of the hip and knee joints and low values of relative torques developed by knee joint extensors increase the risk of injury to the motor system.

The results of the examination of static balance performed with the modified Flamingo Balance Test (Table 3) have shown that there are no statistically significant differences between girls and boys - the mean time of left-sided and right-sided single-leg stance was similar in both groups.

A comparative analysis of the results for dynamic balance assessed with YBT between girls and boys did not reveal any statistically significant differences, either (Table 4). The range of excursions in each examined direction for the left and right lower extremities was similar in both groups. For global results, the difference was estimated to be $0.20 \%$ for the left lower extremity and $0.18 \%$ for the right lower extremity - in both cases in favour of girls.

In order to better illustrate any possible differences between YBT results in girls and in boys, the authors decided to compare the global results achieved in this test with the index defining the limits of better and worse postural stability (Tables 5 and 6) [9]. Girls exceeded the limit value of the index (89.6\%) in $80 \%$ for the right lower limb and in $78 \%$ for the left lower limb; in the group of boys, these percentages were $79 \%$ and $74 \%$, respectively. These results provide a specific confirmation of the outcomes presented in Table 3; girls and boys achieved similar results of dynamic balance measurements.

There is no doubt that both studied groups obtained good results, to a large extent exceeding the limit of the $89.6 \%$ index. This implies that there is only a low risk of injury in both girls and boys. The results achieved by 14 -year-olds of both sexes may indicate that they receive high-level physical education and its curriculum is varied and adapted to the pupils' preferences and interests. Such activities support the development of many motor skills during adolescence, particularly including motor coordination. Girls and boys who did not exceed the $89.6 \%$ index should be recommended to participate in corrective and compensatory activities to reduce the risk of injuries.

It may be interesting to compare the presented results with those achieved with YBT by Chwała [23] in a study of 4 groups of boys of different ages who regularly attended tennis courses. In terms of dynamic balance, the poorest results among the studied age groups were observed among boys aged 13-14 years, where the limit value of the index was exceeded by $80 \%$ of the subjects for the left lower limb and by $91 \%$ of the subjects for the right lower limb. The results reported in the subject literature are very similar to those described in this paper.
The reason for the slightly worse results in this age group may be the fact that young people of this age are in the puberty phase and they are characterized by large physiological changes in their bodies, large disproportions of body anatomy, and worsening of motor skills.

Holden et al. [13] demonstrated in their long-term 24-month study conducted in a group of adolescent girls and boys practising sports (average age: $13 \pm 0.34$ years) that gender determined different postural stability profiles. At each of the 5 measurement time points (at the beginning of the study and at $6,12,18$, and 24 months), the participants of the experiment performed 3 repetitions of YBT in each direction. Among the boys, the results were steadily improving from the first to the last examination, while in the group of girls, this improvement was observed from the first to the third examination only. Positive changes in favour of boys were found particularly in the posterolateral direction. It is worth noting that among the girls, higher values were measured for anterior excursions at each measurement time point.

The authors of the study [13] suggest that YBT be used for monitoring the predisposition to injuries of the motor system, as they believe that deterioration of postural stability (dynamic balance) is associated with an increased risk of lower limb injuries, in particular. Also, the authors made an attempt to create a database of normative results for adolescent individuals, both gender- and age-specific, that would enable other researchers to conduct screening of the predisposition to motor system injuries and that would be a sort of guide to assess the progress of rehabilitation of adolescent sportspeople with motor system injuries. These studies differed from our study and therefore it is difficult to make direct comparisons of the results. In the study by Holden et al. [13], postural stability was assessed for the period of 2 years. During the first year, both study groups behaved similarly. The stability results improved to reach a plateau among girls, while in boys, there was a further progress. In turn, in our study, a single-time evaluation was applied.

According to Kochanowicz and Kucharska [24], as well as Rahmat et al. [25], introducing additional coordination types of exercise to the physical education curriculum could be a way to improve the level of postural stability. The analysis of the results of those studies showed that the group who were additionally involved in the program of postural stability development achieved much better results than the group participating in physical education classes only. This implies that paying greater attention to the improvement of postural stability brings many benefits to the general development and improvement of physical fitness, which significantly reduces the risk of motor system injuries.

In conclusion, researchers present different opinions on the postural stability of adolescents. Predominating are opinions that there are some differences in static and dynamic balance between girls and boys in this specific period of life. The results of our work do not confirm this conclusion. A common denominator of research using YBT is that doctors, physiotherapists, physical education teachers, and trainers should consider incorporating dynamic balance examinations into early identification of motion limitations and functional asymmetries that may in future increase the risk of a motor system injury [26].

\section{Conclusions}

1. The analysis of postural stability conducted in both static and dynamic conditions did not show any statistically significant differences between boys and girls aged 14 years. 
The ability to maintain a stable body posture when there is a changing fulcrum is comparable among girls and boys.

2 . In the group of girls, the index recommended by Butler et al. [9] was exceeded by $78 \%$ of the subjects for the left lower limb and by $80 \%$ of the subjects for the right one, while in the group of boys, these values equalled $74 \%$ and $79 \%$, respectively. This indicates that the risk of motor system injury among the study subjects was low.

3. It seems essential to implement complex postural stability tests among young people who are going through their puberty in order to identify the risk of locomotor system injuries as early as possible.

\section{Disclosure statement}

No author has any financial interest or received any financial benefit from this research.

\section{Conflict of interest}

The authors state no conflict of interest.

\section{References}

1. Matłosz P, Król P, Rzepko M. Static balance of young people [in Polish]. Rzeszów: UR; 2012.

2. Olchowik G, Tomaszewski M, Olejarz P, Warchoł J, Różańska-Boczula M, Maciejewski $\mathrm{R}$. The human balance system and gender. Acta Bioeng Biomech. 2015;17(1): 69-74; doi: 10.5277/ABB-00002-2014-05.

3. Tchórzewski D. Characteristics of the process of maintaining body balance in men and women in standing on unstable ground in one-legged and two-legged positions in terms of lower limb functional asymmetry and somatic build [in Polish]. Kraków: AWF; 2013.

4. Lee D-K, Kim G-M, Ha S-M, Oh J-S. Correlation of the Y-Balance Test with lower-limb strength of adult women. J Phys Ther Sci. 2014;26(5):641-643; doi: 10.1589/jpts. 26.641.

5. Emery CA, Cassidy JD, Klassen TP, Rosychuk RJ, Rowe BB. Development of a clinical static and dynamic standing balance measurement tool appropriate for use in adolescents. Phys Ther. 2005;85(6):502-514; doi: 10.1093/ptj/85.6.502.

6. Olczak A. Human body balance [in Polish]. Warszawa: WL PZWL; 2016.

7. Bressel E, Yonker JC, Kras J, Heath EM. Comparison of static and dynamic balance in female collegiate soccer, basketball, and gymnastics athletes. J Athl Train. 2007;42(1):42-46.

8. Plisky PJ, Rauh MJ, Kaminski TW, Underwood FB. Star Excursion Balance Test as a predictor of lower extremity injury in high school basketball players. J Orthop Sports Phys Ther. 2006;36(12):911-919; doi: 10.2519/jospt. 2006.2244.

9. Butler RJ, Lehr ME, Fink ML, Kiesel KB, Plisky PJ. Dynamic balance performance and noncontact lower extremity injury in college football players: an initial study. Sports Health. 2013;5(5):417-422; doi: 10.1177/19417 38113498703.

10. Herrington L, Hatcher J, Hatcher A, McNicholas M. A comparison of Star Excursion Balance Test reach distances between ACL deficient patients and asymptomatic controls. Knee. 2009;16(2):149-152; doi: 10.1016/j. knee.2008.10.004.

11. Walaszek R, Chwała W, Walaszek K, Burdacki M, Błaszczuk J. Evaluation of the accuracy of the postural stability measurement with the Y-Balance Test based on
Biomech. 2017;19(2):121-128; doi: 10.5277/ABB-00675 -2016-02.

12. Wilczyński J, Bieniek KB. Canonical correlations between somatic features and postural stability in children aged 10-12 years. Med Studies. 2019;35(2):93-99; doi: $10.5114 / \mathrm{ms} .2019 .86327$.

13. Holden S, Boreham C, Doherty C, Wang D, Delahunt E. A longitudinal investigation into the progression of dynamic postural stability performance in adolescents. Gait Posture. 2016;48:171-176; doi: 10.1016/j.gaitpost.2016.04.019.

14. Paterno MV, Schmitt LC, Ford KR, Rauh MJ, Myer GD, Huang B, et al. Biomechanical measures during landing and postural stability predict second anterior cruciate ligament injury after anterior cruciate ligament reconstruction and return to sport. Am J Sports Med. 2010;38(10): 1968-1978; doi: 10.1177/0363546510376053.

15. Doherty C, Bleakley C, Hertel J, Caulfield B, Ryan J, Delahunt $E$. Recovery from a first-time lateral ankle sprain and the predictors of chronic ankle instability: a prospective cohort analysis. Am J Sports Med. 2016;44(4):9951003; doi: 10.1177/0363546516628870.

16. Velotta J, Weyer J, Ramirez A, Winstead J, Bahamonde R. Relationship between leg dominance tests and type of task. Port J Sport Sci. 2011;11(Suppl. 2):1035-1038.

17. Dobosz J. Scoring tables for the Eurofit, International, and Cooper tests for male and female primary school students [in Polish]. Warszawa: AWF; 2012.

18. Robinson R, Gribble P. Kinematic predictors of performance on the Star Excursion Balance Test. J Sport Rehabil. 2008;17(4):347-357; doi: 10.1123/jsr.17.4.347.

19. Plisky PJ, Gorman PP, Butler RJ, Kiesel KB, Underwood FB, Elkins B. The reliability of an instrumented device for measuring components of the Star Excursion Balance Test. N Am J Sports Phys Ther. 2009;4(2):92-99.

20. Shaffer SW, Teyhen DS, Lorenson CL, Warren RL, Koreerat CM, Straseske CA, et al. Y-Balance Test: a reliability study involving multiple raters. Mil Med. 2013;178(11): 1264-1270; doi: 10.7205/MILMED-D-13-00222.

21. Karimi MT, Solomonidis S. The relationship between parameters of static and dynamic stability tests. J Res Med Sci. 2011;16(4):530-535.

22. Hrysomallis C, McLaughlin P, Goodman C. Balance and injury in elite Australian footballers. Int J Sports Med. 2007;28(10):844-847; doi: 10.1055/s-2007-964897.

23. Chwała W. Profiled tennis classes aimed at correcting musculoskeletal dysfunctions and posture and improving internal organ function. Kraków: Final report within the framework of the Regional Operational Programme for the Małopolska Region 2014-2020; Priority Axis 1. Knowledge economy; Action 1.2. Research and innovation in enterprises; Sub-action 1.2.3. Innovation vouchers from the European Regional Development Fund [in Polish]; 2016.

24. Kochanowicz K, Kucharska E. Body balance in children aged 11-13 years and the process of physical education. Pol J Sport Tourism. 2010;17:87-96.

25. Rahmat A, Naser H, Belal M, Hasan D. The effect of core stabilization exercises on the physical fitness in children 9-12 years. Med Sport. 2014;10(3):2401-2405.

26. Gorman PP, Butler RJ, Plisky PJ, Kiesel KB. Upper quarter Y-Balance Test: reliability and performance comparison between genders in active adults. J Strength Cond Res. 2012;26(11):3043-3048; doi: 10.1519/JSC.0b013e $3182472 \mathrm{fdb}$. 